\title{
Hidrothermal liquefaction of lignocellulosic residue to produce sustainable materials: fractions characterization
}

\author{
Solange Kazue Utimura ${ }^{1 *}$ (1) \\ Denise Crocce Romano Espinosa ${ }^{1}$ \\ Marco Antonio das Neves ${ }^{2}$ \\ Isao Kobayashi ${ }^{3}$ \\ Mitsutoshi Nakajima ${ }^{2}$ \\ Cristina Stewart Bogsan ${ }^{4}$
}

\begin{abstract}
In this study, hydrothermal liquefaction (HTL) of sugarcane bagasse (SCB) acquired in Okinawa (Japan) was performed at 170,200 and $230^{\circ} \mathrm{C}$, pressures from 1 to $3 \mathrm{MPa}$ and retention time of $30 \mathrm{~min}$. These experiments were executed in a $500 \mathrm{~mL}$ reactor with $5 \mathrm{~g} \mathrm{SCB}$ and $95 \mathrm{~mL}$ deionized water in inert nitrogen condition. The highest sugar yields were obtained at the concentration of $20.25 \mathrm{~g} / \mathrm{L}$ at $230{ }^{\circ} \mathrm{C}, 3 \mathrm{MPa}$ and $30 \mathrm{~min}$. In accordance with elemental analysis, highest carbon content values were $55.31 \%$ at $200{ }^{\circ} \mathrm{C}$ and $59.9 \%$ at $230{ }^{\circ} \mathrm{C}$. The chemical composition was analyzed through SEM and FTIR. HTL has been applied to obtain biomaterials from agricultural wastes which can be incorporated or converted into new value-added products. HTL in subcritical conditions is an interesting hydrolysis process and has advantages of reduced energy consumption and water reaction environment.
\end{abstract}

Keywords: Hydrothermal liquefaction; Sugarcane bagasse; Subcritical conditions; Lignocellulosic residues; Materials; Waste.

\section{Introduction}

Lignocellulosic biomass from agricultural wastes is an important source for the increment of products from renewable materials. Sugarcane bagasse $(\mathrm{SCB})$ is a lignocellulosic residue and the most uses for SCB is combustion for energy production that can be applied to replace fossil fuel resources [1].

This renewable waste has a potential to be considered as a substrate for the production of valuable chemical elements including prebiotics biomolecules and bioactivities of phenolic compounds [2]. Chemical compounds that can be achieved from SCB possess properties of value in production of polymeric materials, functional food, pharmaceutical, and health applications [3]. An alternative approach for converting lignocellulosic biomass into low-molecular weight compounds is HTL in subcritical conditions [4]. At subcritical conditions, water has state that are defined, the critical point below values at $374.2{ }^{\circ} \mathrm{C}$ and $22.1 \mathrm{MPa}$ [5]. HTL process starts with the dissolution of biomass into the water at $100^{\circ} \mathrm{C}$ and hydrolysis above $150^{\circ} \mathrm{C}$, resulting the decomposition of the cellulose and hemicellulose parts into short-chain monomers. The formation of slurry, biofuels and char occurs in HTL conditions above $200^{\circ} \mathrm{C}$ and $1 \mathrm{MPa}$ [6].
These monomeric compounds can be converted into a range of value-added chemicals and biomaterials [7]. The aim of this work was to study HTL technique on the deconstruction of the cell wall polymers and fractions characterization from SCB.

\section{Materials and methods}

\subsection{SCB characterization}

SCB was supplied by Okinawa Prefectural Agricultural Research Center in Japan. SCB was size-reduced with a sieved blender with an average size of $1 \mathrm{~mm}$. The composition of $\mathrm{SCB}$ was analyzed such as moisture, ash and total extractives contents. The composition of the holocellulose, $\alpha$-cellulose and lignin were determined through chemical analysis.

\subsection{HTL of SCB}

HTL experiments in subcritical water at temperatures $\left(170-200{ }^{\circ} \mathrm{C}\right)$ were performed with $5 \mathrm{~g}$ of BSC sample.

${ }^{\prime}$ Engenharia Química, Escola Politécnica, Universidade de São Paulo - USP, São Paulo, SP, Brasil.

${ }^{2}$ Department of Life and Environmental Sciences, University of Tsukuba, Tsukuba, Japan.

${ }^{3}$ National Agriculture and Food Research Organization, Tsukuba, Japan.

${ }^{4}$ Faculdade de Ciências Farmacêuticas, Universidade de São Paulo - USP, São Paulo, SP, Brasil.

*Corresponding author: solange.utimura@alumni.usp.br 
These experiments were performed in an HTL batch-type reactor. The reactor was equipped with nitrogen gas inlet and outlet valves, pressure gage, back pressure valve, internal stirrer and thermocouple. The ratio of sample to distilled water was 1:19 $(\mathrm{g} / \mathrm{mL})$. HTL experiments were carried out in $30 \mathrm{~min}$. The hydrolase products were collected and the mixture was filtrated (Paper Whatman G/F, diameter $4.7 \mathrm{~cm}$, pre-size $1.2 \mu \mathrm{m}$ ) under vacuum (Ulvac Kiko MDA-015) and the solid was dried at $105^{\circ} \mathrm{C}$ for 6 hours. The liquid products were collected and the $\mathrm{pH}$ was determined. The solid mass was determined by the difference among the initial amount of sample and the residual solid remaining in the HTL process. Analysis of microstructure of the surface of sugarcane straw was performed before and after the HTL hydrolysis $\left(170^{\circ} \mathrm{C}\right.$, $200{ }^{\circ} \mathrm{C}$, and $230^{\circ} \mathrm{C}$ ). The SEM equipment was a scanning electron microscopy (HITACHI Miniscope TM-1000, Japan).

\subsection{Fractions analysis}

Elemental analysis was performed on $\mathrm{SCB}$ and the solid fraction after HTL experiments. The elemental composition was determined by using a CHN analyzer (Perkin-Elmer $2400 \mathrm{II}$ ) at Department of Chemistry, University of Tsukuba. The SEM equipment was a scanning electron microscopy (HITACHI Miniscope TM-1000). Fourier Transform Infrared Spectrometer (Jasco FT/IR-300) was used for qualitative analysis. Dry powder samples were prepared on a Retsch ZM 200 and spectra collected at $4 \mathrm{~cm}-1$ resolutions with $400-4000 \mathrm{~cm}^{-1}$ spectral range.

\section{Results and discussion}

\subsection{Composition of SCB}

The chemical composition of SCB was detailed in Table 1. The disposal of bagasse ash has been employed as a fertilizer due to the presence of potassium and phosphorus. Another application is a mixture of bagasse ash with sand and alkalis that can be used for the manufacture of glass bottles and a filtering aid [8].

The differences in chemical composition of the sugarcane may be possible due to characteristics, cultivations and conditions such as temperature and storage time. The discrepancies in the characterization methods may also include the extractives for lignin and holocellulose analysis and the treatment with different solvents [6].

\subsection{HTL experiments}

During HTL, the reaction temperature is an important process parameter, and depending on the temperature, the biopolymer degradation and H-bonding networking in lignocellulose would be broken and hydroxyl groups would be oxidized to carboxyl. Hydrolysis of hemicellulose does not start until the temperature exceeds $170^{\circ} \mathrm{C}$ with the increasing sugar yield and temperature [8]. This effect could be associated with the thermal effects on hydrolysis kinetics and the increased self-ionization constant of water. So, this effect increased the concentration of $\mathrm{H}^{+}$and $\mathrm{OH}^{-}$in the reaction and promotes the acid catalyzed hydrolysis of hemicellulose and cellulose [9]. At supercritical condition pressure has limited the effect on physico-chemical properties of water $[10,11]$.

\subsection{Analysis of fractions}

The yields of reducing sugars obtained at different conditions of temperature at HTL tests are shown in Table 2. The hydrolysis of hemicellulose was sufficient for disrupting the structure of SCB. The lowest yield was achieved at $170{ }^{\circ} \mathrm{C}$ and increased on increasing temperature to 230 from $170^{\circ} \mathrm{C}$. Many works suggested that the hemicellulose would be hydrolyzed at temperature range of $190-230{ }^{\circ} \mathrm{C}$ [12].

\subsubsection{Elemental composition}

The elemental analysis was performed and samples of $1.5 \mathrm{~g}$ of dry SCB were weighed to the auto sampler and the results are presented in Table 3. With the increase in temperature, the $\mathrm{O} / \mathrm{C}$ and $\mathrm{H} / \mathrm{C}$ atomic ratio decreased. The ratio of $\mathrm{H} / \mathrm{C}$ is an index of aromaticity and the sorption capacity of hydrophobic organic compounds [13]. The different feature of organic substances and the variation of $\mathrm{H} / \mathrm{C}$ and $\mathrm{O} / \mathrm{C}$ relation are considered the oxidation and reduction reactions that would change the ratio of $\mathrm{O} / \mathrm{C}$ but not of $\mathrm{H} / \mathrm{C}$. Therefore, the stability of $\mathrm{H} / \mathrm{C}$ during the oxidation reactions was suitable, which the oxidation of aromatic hydrocarbon only changed the atomic ratio of $\mathrm{O} / \mathrm{C}$ [14].

\subsubsection{Morphology and FTIR spectra}

The SEM images of residual solid obtained after HTL hydrolysis are shown in Figure 1. According the

Table 1. Chemical composition of SCB (wt \%)

\begin{tabular}{lr}
\hline Moisture & $7.95 \pm 0.01$ \\
Ash & $3.51 \pm 0.11$ \\
Acetone/ethanol/cyclohexane extractible & $4.48 \pm 0.21$ \\
Acid-soluble lignin & $1.35 \pm 0.10$ \\
Holocellulose & $70.08 \pm 0.10$ \\
a-cellulose & $44.91 \pm 0.10$ \\
Hemicellulose & $32.17 \pm 0.09$ \\
Cellulose & $35.12 \pm 0.10$ \\
\hline
\end{tabular}

Table 2. Reducing Sugar yield by HTL in different temperature

\begin{tabular}{cc}
\hline Temperature $\left({ }^{\circ} \mathbf{C}\right)$ & Reducing Sugar Yield $(\mathrm{g} / \mathbf{L})$ \\
\hline 170 & $9.9394 \pm 2.40$ \\
200 & $17.7759 \pm 1.01$ \\
230 & $20.2562 \pm 2.27$ \\
\hline
\end{tabular}


HTL hydrolysis, at $170{ }^{\circ} \mathrm{C}$ showed cracks on structure and lignocellulosic parts liberated from biomass. At $200{ }^{\circ} \mathrm{C}$, residual solid showed more cracks on surface with disruption of structure (Figure 2). By raising temperature to $230^{\circ} \mathrm{C}$, solid residues became more particulates on surface with disrupted structure and agglomerates (Figure 3). This solid residue was formed probably due the minerals during the decomposition processes $[15,16]$.

Figure 4 shows the spectra of the sugarcane bagasse after HTL hydrolysis at $170^{\circ} \mathrm{C}$. The FTIR spectra has shown the absorption peaked bands between $2910 \mathrm{~cm}^{-1}$ and 2918

Table 3. Elemental analysis of SCB after and before HTL

\begin{tabular}{crrrr}
\hline & SCB & HTL 170 ${ }^{\circ} \mathbf{C}$ & HTL 200 ${ }^{\circ} \mathbf{C}$ & HTL 230 ${ }^{\circ} \mathbf{C}$ \\
\hline $\mathrm{C} \%$ & 44.24 & $50.48 \pm 0.73$ & $55.31 \pm 0.86$ & $59.90 \pm 0.04$ \\
$\mathrm{H} \%$ & 6.13 & $6.08 \pm 0.09$ & $5.77 \pm 0.03$ & $5.49 \pm 0.02$ \\
$\mathrm{~N} \%$ & 0.22 & $0.45 \pm 0.05$ & $0.52 \pm 0.02$ & $0.51 \pm 0.01$ \\
$\mathrm{O} \%$ & 45.90 & $41.44 \pm 0.59$ & $36.85 \pm 0.85$ & $31.94 \pm 0.02$ \\
$\mathrm{Ash} \%$ & 3.51 & $1.54 \pm 0.10$ & $1.55 \pm 0.10$ & $2.10 \pm 0.10$ \\
$\mathrm{H} / \mathrm{C}$ & 1.65 & $1.44 \pm 0.04$ & $1.27 \pm 0.01$ & $1.10 \pm 0.01$ \\
$\mathrm{O} / \mathrm{C}$ & 0.77 & $0.61 \pm 0.02$ & $0.50 \pm 0.02$ & $0.40 \pm 0.01$ \\
\hline
\end{tabular}

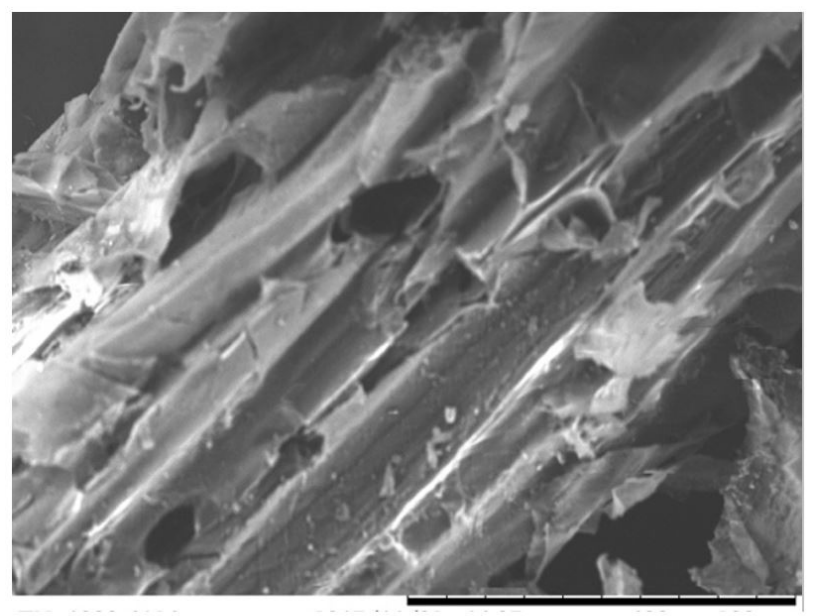

X400 $200 \mu \mathrm{m}$

Figure 1. Image analyzed by SEM of residual solid after HTL hydrolysis at $170{ }^{\circ} \mathrm{C}$.

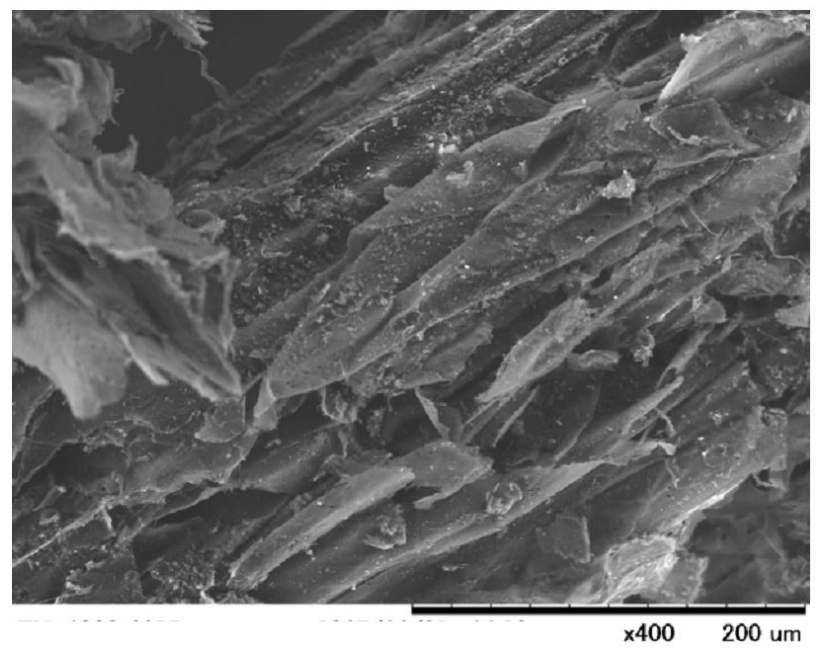

Figure 2. Image from SEM of solid residue analysed after the HTL hydrolysis at $200^{\circ} \mathrm{C}$.

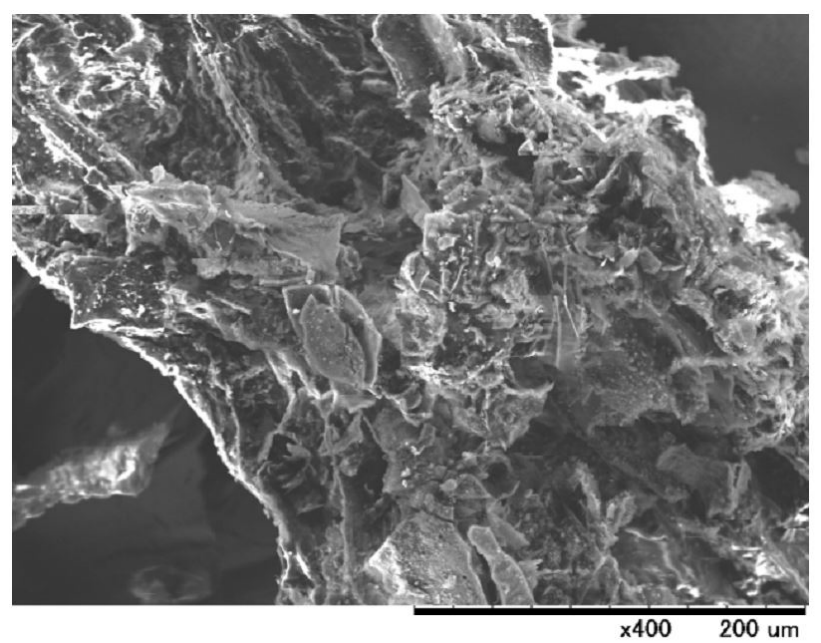

Figure 3. SEM analysis result of residual solid after the HTL hydrolysis at $230{ }^{\circ} \mathrm{C}$.

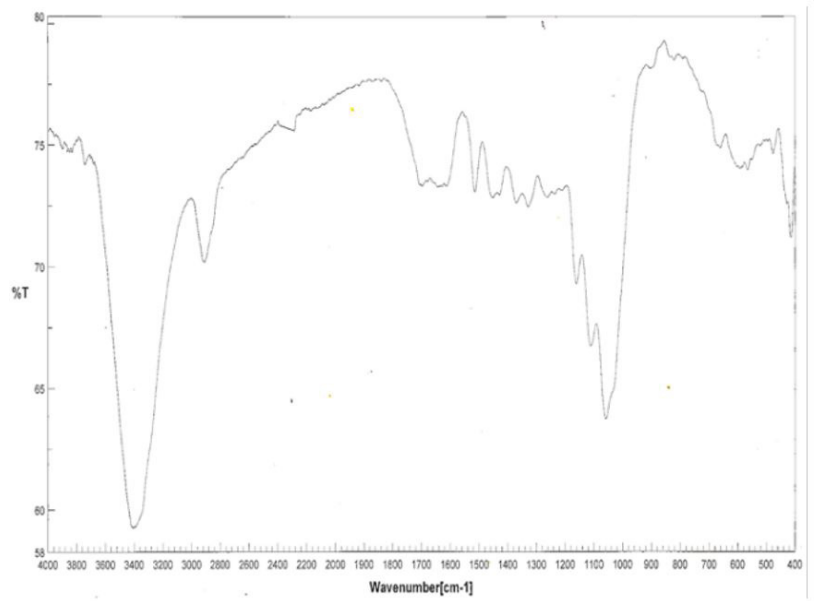

Figure 4. FTIR spectra after HTL hydrolysis at $170{ }^{\circ} \mathrm{C}$. 
$\mathrm{cm}^{-1}$ that can be attributed to the methyl group. The spectra from 3100 to $2700 \mathrm{~cm}^{-1}$ is associated with $\mathrm{C}-\mathrm{H}$ stretching peaks that become distinguished with increasing hydrolysis processes [14]. The lignin become less present at hydrolysis temperature of $200{ }^{\circ} \mathrm{C}$ and $230{ }^{\circ} \mathrm{C}$ that may be due the deposition of sub products on the surface. The spectra at 200-230 ${ }^{\circ} \mathrm{C}$ has shown bands at $1609 \mathrm{~cm}^{-1}$ to $1510 \mathrm{~cm}^{-1}$ can be associated with aromatic bonds. The bands from $1400 \mathrm{~cm}^{-1}$ to $800 \mathrm{~cm}^{-1}$ can be associated with $\mathrm{C}-\mathrm{O}$ stretches and other functional groups as $\mathrm{C}-\mathrm{O}-\mathrm{C}$ and $\mathrm{C}-\mathrm{H}$ [13].

\section{Conclusions}

The evaluation of the hydrothermal liquefaction (HTL) in subcritical water conditions has demonstrated potential to convert lignocellulosic biomass into a wide range of value-added compounds for further chemical processing. The association of HTL process with subsequent technologies such as saccharification processes should be a direction in improving the economic viability of the production of sugar and its other transformation. These experiments achieved the possibility of the biomass hydrolysis in according at the conditions examined here.

\section{Acknowledgements}

This study was supported by Jasso Exchange Program, Trans-Pacific Human Capital Development, University of Tsukuba, Japan. The authors wish to thank the Fundação de Amparo a Pesquisa do Estado de São Paulo (FAPESP) and the Conselho Nacional de Desenvolvimento Científico e Tecnológico (CNPq), São Paulo, Brazil for PhD scholarship (Process No. 141086/2015-7) and financial support (Process No. 870243/1997-7).

\section{References}

1 Kumar G, Dharmaraja J, Arvindnarayan S, Shoban SP, Bakonyi P, Saratale GD, et al. A comprehensive review on thermochemical, biological, biochemical and hybrid conversion methods of bio-derived lignocellulosic molecules into renewable fuels. Fuel. 2019;251:352-367.

2 Cho EJ, Trinh LTP, Song Y, Lee YG, Bae HJ. Bioconversion of biomass waste into high value chemicals. Bioresource Technology. 2020;298:122386.

3 Mayanga-Torres PC, Lachos-Perez D, Rezende CA, Prado JM, Ma Z, Tompsett GT, et al. Valorization of coffee industry residues by subcritical water hydrolysis: recovery of sugars and phenolic compounds. The Journal of Supercritical Fluids. 2017;120:75-85.

4 Baloch HA, Nizamuddin S, Siddiqui MTH, Mubarak NM, Dumbre DK, Srinivasan MP, et al. Sub-supercritical liquefaction of sugarcane bagasse for production of bio-oil and char: effect of two solvents. Journal of Environmental Chemical Engineering. 2018;6(5):6589-6601.

5 Jiang W, Kumar A, Adamopoulos S. Liquefaction of lignocellulosic materials and its applications in wood adhesives - A review. Industrial Crops and Products. 2018;124:325-342.

6 Kumar M, Oyedun AO, Kumar A. A review on the current status of various hydrothermal technologies on biomass feedstock. Renewable \& Sustainable Energy Reviews. 2018;81:1742-1770.

7 Isikgor FH, Remzi Becer C. Lignocellulosic biomass: a sustainable platform for production of bio-based chemicals and polymers. Polymer Chemistry. 2015;6(25):4497-4559.

8 Rao Y, Xiang B. Determination of total ash and acid-insoluble ash of chinese herbal medicine Prunellae Spica by infrared spectroscopy. Yakugaku Zasshi. 2009;129(7):881-886.

9 Abdelmoez W, Nage SM, Bastawess A, Ihab A, Yoshida H. Subcritical water technology for wheat straw hydrolysis to produce value added products. Journal of Cleaner Production. 2014;70:68-77.

10 Zhu G, Zhu X, Fan Q, Wan X. Production of reducing sugars from bean dregs waste by hydrolysis in subcritical water. Journal of Analytical and Applied Pyrolysis. 2011;90(2):182-186.

11 Prado JM, Follegatti-Romero LA, Forster-Carneiro T, Rostagno MA, Maugeri F Fo, Meireles MAA. Hydrolysis of sugarcane bagasse in subcritical water. The Journal of Supercritical Fluids. 2014;86:15-22.

12 Toor SS, Rosendahl L, Rudolf A. Hydrothermal liquefaction of biomass: a review of subcritical water technologies. Energy. 2011;36(5):2328-2342.

13 Lachos-Perez D, Martinez-Jimenez F, Rezende CA, Tompsett G, Timko M, Forster-Carneiro T. Subcritical water hydrolysis of sugarcane bagasse: an approach on solid residues characterization. The Journal of Supercritical Fluids. 2016;108:69-78. 
14 Russo C, Stanzione F, Tregrossi A, Ciajolo A. Infrared spectroscopy of some carbon-based materials relevant in combustion: qualitative and quantitative analysis of hydrogen. Carbon. 2014;74:127-138.

15 Peng TY, Wu SB. The structural and thermal characteristics of wheat straw hemicelluloses. Journal of Analytical and Applied Pyrolysis. 2010;88(2):134-139.

16 Bian J, Peng F, Peng XP, Xu F, Sun RC, Kennedy JF. Isolation of hemicelluloses from sugarcane bagasse at different temperatures: structure and properties. Carbohydrate Polymers. 2012;88(2):638-645.

Received: 23 Sep. 2020

Accepted: 8 Jan. 2021 